\title{
Ensino da homeopatia na graduação em farmácia: concepções e práticas pedagógicas em instituiç̧̃̃es do estado do Rio de Janeiro
}

Anderson Domingues Corrêa ${ }^{1}$

Sidnei Quezada Meireles Leite ${ }^{2}$

CORRÊA, A.D.; LEITE, S.Q.M. The teaching of homeopathy in pharmacy undergraduation: pedagogical conceptions and practices in institutions from the state of Rio de Janeiro.

Interface - Comunic., Saúde, Educ., v.12, n.25, p.267-80, abr./jun. 2008.

This work addresses the situation of homeopathy education carried out in the pharmacy faculties of the state of Rio de Janeiro, seeking to identify and analyze the political and pedagogical situation with regard to the curricular perspective of the education of the generalist pharmacists, in relation to the Brazilian Curricular Policies for the Pharmacy Undergraduation Courses. Legal aspects and the reports of teachers were addressed, showing that the homeopathy teaching in the State of Rio de Janeiro is offered by two public universities and 12 private institutions. While homeopathy teaching in public universities is an extracurricular discipline, the majority of the private institutions offers it as an obligatory one. Both in undergraduation as in specialization courses in homeopathy, the focus is the preparation of drugs, including a theoretical approach to the philosophy of homeopathy.

Keywords: Homeopathy. Pharmacy teaching. Pharmacy. Curriculum. Higher education.
Este trabalho aborda a situação do ensino de homeopatia nas faculdades de farmácia do estado do Rio de Janeiro, buscando identificar e analisar a situação políticopedagógica com relação à perspectiva curricular de formação do farmacêutico generalista, tendo em vista as Diretrizes Curriculares Nacionais do Curso de Graduação em Farmácia. Discutem-se os aspectos legais da questão e as percepções dos professores a respeito. $O$ ensino de homeopatia no estado do Rio de Janeiro é oferecido por duas universidades públicas e 12 instituições particulares, sendo que nas públicas a disciplina é optativa e nas particulares, em sua maioria, é obrigatória. Tanto na graduação quanto na especialização em homeopatia, o foco é o preparo de medicamentos, incluindo uma abordagem teórica da filosofia homeopática.

Palavras-chave: Homeopatia. Ensino de farmácia. Farmácia. Currículo. Educação superior.

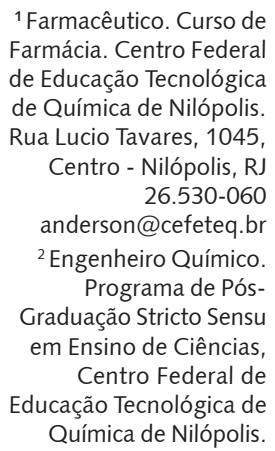

${ }^{1}$ Farmacêutico. Curso de Farmácia. Centro Federal de Educação Tecnológica de Química de Nilópolis. Rua Lucio Tavares, 1045 , Centro - Nilópolis, RJ 26.530-060 anderson@cefeteq.br ${ }^{2}$ Engenheiro Químico. Programa de PósGraduação Stricto Sensu em Ensino de Ciências, Centro Federal de Educação Tecnológica de Química de Nilópolis. 


\section{Introdução}

A publicação da Lei de Diretrizes e Bases da Educação Nacional (LDB), em 1996, e da resolução CNE/CES n.2, em 2002, que tratava das Diretrizes Curriculares Nacionais do Curso de Graduação em Farmácia, fez com que as instituições de ensino superior (IES) repensassem sua prática pedagógica, para adequar seus currículos à formação de farmacêuticos generalistas. Assim, as faculdades tiveram que definir as subáreas de conhecimento da farmácia que passariam a estar presentes nos currículos de graduação; entre elas, a farmácia homeopática.

Em 1996, o Ministério da Educação criou uma comissão de especialistas de ensino de farmácia para elaborar um estudo sobre a formação do farmacêutico e as demandas do mercado de trabalho. As discussões sobre as necessidades dessa formação resultaram na apresentação de propostas de inclusão dos conteúdos de homeopatia como disciplina obrigatória nos currículos de graduação em farmácia, durante a I Conferência Nacional de Educação Farmacêutica, ocorrida em Brasília, no ano 2000 (De La Cruz, 2001).

A resolução n.440, publicada em 26 de outubro de 2005, deu nova redação à resolução n.335, de 1998, habilitando o farmacêutico que provasse efetivo exercício profissional de pelo menos um ano na área, em farmácia homeopática legalmente habilitada, à responsabilidade técnica sobre a farmácia que manipula medicamento homeopático, o que praticamente acabava com a capacitação formal para a habilitação em farmácia homeopática (Conselho Federal de Farmácia - CFF, 2005). Logo após a publicação dessa resolução, representantes da Associação Brasileira de Farmacêuticos Homeopatas (ABFH) compareceram a uma plenária para debater os pré-requisitos exigidos para a manipulação de medicamentos homeopáticos. Foi convocada uma reunião da ABFH com a Comissão de Farmácia do CFF, para discutir sugestões de mudança no texto. Assim, em 15 de maio de 2006, foi publicada uma retificação da resolução n.440, de 2005 , que retirou a prova de um ano no exercício profissional na área para se habilitar o profissional e acrescentou os limites mínimos de carga horária: sessenta horas para a disciplina de homeopatia e duzentos e quarenta horas para o estágio (CFF, 2006).

Portanto, de acordo com a legislação em vigor, os Conselhos Regionais de Farmácia (CRF) consideram habilitado a assumir a responsabilidade técnica de farmácia ou laboratório industrial homeopático o farmacêutico que comprovar uma das seguintes qualificações:

I ter cursado a disciplina de homeopatia com, no mínimo, sessenta horas, no curso de graduação de farmácia, complementada com estágio em manipulação e dispensação de medicamentos homeopáticos de, no mínimo, duzentas e quarenta horas, na própria IES, em farmácias que manipulem medicamentos homeopáticos ou em laboratórios industriais de medicamentos homeopáticos conveniados a instituições de ensino;

Il possuir título de especialista ou curso de especialização em farmácia homeopática que atenda às resoluções pertinentes do CFF, em vigor.

III comprovar o exercício da responsabilidade técnica em estabelecimentos farmacêuticos que preparam medicamentos homeopáticos, tendo obtido a comprovação até a data da publicação da resolução n.319, de 30 de outubro de 1997.

Dessa forma, algumas faculdades de farmácia do estado do Rio de Janeiro reestruturaram a disciplina de homeopatia, inclusive em termos de carga horária, garantindo aos profissionais formados o direito, junto ao CRF, de exercer a responsabilidade técnica sobre farmácia ou laboratório industrial homeopático. Cabe citar que o alto número de instâncias e fóruns dentro da universidade que fazem parte dos trâmites legais para a aprovação dos documentos internos é um dos principais obstáculos à implantação dos projetos pedagógicos das faculdades de farmácia.

Dados da ABFH publicados em 2000 mostraram que cerca de 60\% das faculdades de farmácia brasileiras ofereciam, então, disciplinas de homeopatia. Ainda segundo a $\mathrm{ABFH}$, a carga horária dessas disciplinas variava de trinta a 144 horas, e cerca de $60 \%$ das IES públicas ofereciam as disciplinas de forma obrigatória (ABFH, 2000). A ABFH foi criada em 1990, e a homeopatia foi reconhecida como especialidade farmacêutica pelo CFF em 1992, por meio da resolução n.232/1992. Segundo Meirelles (1991), o ensino de farmacotécnica homeopática passou a ser obrigatório nas faculdades de farmácia do Brasil a partir de 1952, com a lei n.1.552. No entanto, essa legislação deixou de ser cumprida a partir de 
1960. Cabe citar que, em 1966, durante o governo Castelo Branco, foram publicadas portarias com instruções de instalação e funcionamento de farmácias homeopáticas e industrialização de medicamentos e, em 1979, houve a criação da Associação Médica Homeopática Brasileira (AMHB).

A primeira farmácia homeopática do Brasil foi criada em 1843 pelo introdutor da homeopatia no país, o médico francês Benoit Jules Mure, com a denominação de Botica Homeopática Central (Galhardo, 1928). O reconhecimento oficial da homeopatia como especialidade médica só veio em 1980, com a resolução n.1000, do Conselho Federal de Medicina. Dessa forma, com esse reconhecimento, a especialidade deixou de ser tratada como "terapia alternativa" (Corrêa et al., 2006; Corrêa, Siqueira-Batista, Quintas, 1997).

A implementação da homeopatia na rede pública de saúde iniciou-se em 1985, com a celebração de convênio entre o Instituto Nacional de Assistência Médica da Previdência Social (Inamps), a Fundação Oswaldo Cruz (Fiocruz), a Universidade do Estado do Rio de Janeiro (UERJ) e o Instituto Hahnemanniano do Brasil (IHB). Tal convênio teve como intuito institucionalizar a assistência homeopática na rede pública de saúde do país. Entre essa data e os dias atuais, foram realizados vários eventos e promulgadas várias legislações, até a publicação da portaria n.971 do Ministério da Saúde, de 3 de maio de 2006. Essa portaria aprovou a Política Nacional de Práticas Integrativas e Complementares, dentre as quais se encontra a homeopatia, no Sistema Único de Saúde - SUS (Brasil, 2006).

Com a criação do SUS e a descentralização da gestão, ampliou-se a oferta de atendimento homeopático. Esse avanço pode ser observado no número de consultas em homeopatia, que, desde sua inserção como procedimento na tabela do SIA/SUS, vem apresentando crescimento anual em torno de $10 \%$. No ano de 2003, o sistema de informação do SUS e os dados do diagnóstico realizado pelo Ministério da Saúde em 2004 revelaram que a homeopatia está presente na rede pública de saúde em vinte unidades da federação, 16 capitais, 158 municípios, contando com registro de 457 profissionais médicos homeopatas (Brasil, 2006).

Embora ocorra constante aumento da oferta de serviços, a assistência farmacêutica em homeopatia não acompanha essa tendência. Conforme levantamento da AMHB, realizado em 2000, apenas 30\% dos serviços de homeopatia da rede SUS forneciam medicamento homeopático. Dados do levantamento realizado pelo Ministério da Saúde em 2004 revelam que apenas 9,6\% dos municípios que informaram ofertar serviços de homeopatia possuíam farmácia pública de manipulação (Brasil, 2006).

Este trabalho, portanto, aborda a situação do ensino de homeopatia nas faculdades de farmácia do estado do Rio de Janeiro, buscando identificar e analisar a situação político-pedagógica com relação à perspectiva curricular de formação do farmacêutico generalista. Discutem-se os aspectos legais da questão e as percepções dos professores com relação ao ensino de homeopatia e suas possíveis articulações com o mercado de trabalho.

\section{Percurso metodológico}

Este trabalho refere-se a uma pesquisa exploratória, com abordagem qualitativa, realizada no período de 2004 a 2006, mediante análise documental, entrevistas com professores de homeopatia e coordenadores de curso de farmácia de IES do estado do Rio de Janeiro. Desenvolveu-se no Programa de Pós-Graduação stricto sensu em Ensino de Biociências e Saúde da Fundação Oswaldo Cruz (Fiocruz) e foi aprovado pelo Comitê de Ética em Pesquisa dessa instituição.

A pesquisa consistiu no levantamento de aspectos da situação do ensino de homeopatia nas faculdades de farmácia do estado do Rio de Janeiro. Procedeu-se a uma análise das percepções docentes com uma perspectiva curricular, buscando identificar a situação político-pedagógica do ensino de homeopatia com relação à formação do farmacêutico generalista, tendo em vista as Diretrizes Curriculares Nacionais do Curso de Graduação em Farmácia (Conselho Nacional de Educação - CNE, 2002).

Participaram da pesquisa 14 IES, listadas no Quadro 1. Embora o Centro Federal de Educação Tecnológica de Química de Nilópolis - RJ passasse a oferecer o curso de graduação em farmácia em 2008 , só foram discutidos os dados coletados no período supracitado. 
ENSINO DE HOMEOPATIA NA GRADUAÇÃO..

Quadro 1. Lista de Instituições de Ensino Superior que ministram cursos superiores de farmácia no estado do Rio de Janeiro e que fizeram parte do estudo da situação do ensino de homeopatia.

\begin{tabular}{|c|l|l|}
\hline & \multicolumn{1}{|c|}{ IES } & \multicolumn{1}{|c|}{ MUNICíPIO } \\
\hline 1 & Centro Universitário Augusto Motta - UNISUAM & Rio de Janeiro \\
\hline 2 & Centro Universitário Celso Lisboa - CEUCEL & Rio de Janeiro \\
\hline 3 & Centro Universitário de Barra Mansa - UBM & Barra Mansa \\
\hline 4 & Centro Universitário Plínio Leite - UNIPLI & Niterói \\
\hline 5 & Faculdade Bezerra de Araújo - FABA & Rio de Janeiro \\
\hline 6 & Faculdade de Medicina de Campos - FMC & Campos de Goytacazes \\
\hline 7 & Universidade do Grande Rio “Professor José de Souza Herdy" - & Duque de Caxias - São João de Meriti \\
\hline 8 & UnIGRANRIO & Rio de Janeiro (2) e Campos de Goytacazes \\
\hline 9 & Universidade Federal do Rio de Janeiro - UFRJ & Rio de Janeiro \\
\hline 10 & Universidade Federal Fluminense - UFF & Niterói \\
\hline 11 & Universidade Gama Filho - UGF & Rio de Janeiro \\
\hline 12 & Universidade Iguaçu - UNIG & Itaperuna e Nova Iguaçu \\
\hline 13 & Universidade Salgado de Oliveira - UNIVERSO & Niterói e São Gonçalo \\
\hline 14 & Universidade Severino Sombra - USS & Vassouras \\
\hline
\end{tabular}

Fonte: Censo de 2004 do ensino superior publicado pelo INEP/MEC.

Os sujeitos que fizeram parte do estudo da situação do ensino de homeopatia foram sete professores de homeopatia e dez coordenadores de graduação em farmácia das IES do estado do Rio de Janeiro.

A coleta de dados foi realizada por meio de análise de documentos oficiais das instituições, registros e observações feitas ao longo da pesquisa, uma extensa pesquisa bibliográfica em livros e documentos históricos, além de entrevistas semi-estruturadas realizadas com os professores das disciplinas de homeopatia e coordenadores de alguns cursos de farmácia. Antes de cada entrevista, o depoente era informado de que aqueles dados fariam parte de um estudo de educação e de que sua participação era voluntária.

A análise dos dados foi realizada com base nas recomendações de Bardin (2004). As entrevistas foram transcritas, e os textos, tabulados e categorizados de acordo com os temas abordados, buscandose identificar as idéias centrais seguindo a técnica de Lefèvre e Lefèvre (2000), a fim de se obter a análise do discurso com base nos trechos da fala. Vale lembrar que, em alguns momentos do texto, preferiu-se utilizar o relato fiel, porque entendemos que sua utilização, nesse caso, pode contribuir mais para as discussões. Para garantir a integridade dos sujeitos envolvidos, utilizou-se um código para as citações de suas falas em texto.

\section{O ensino de homeopatia na graduação em farmácia}

Segundo o Censo de 2004 do ensino superior, publicado pelo Instituto Nacional de Estudos e Pesquisas Educacionais do Ministério da Educação (INEP/MEC), o número de cursos superiores de farmácia em funcionamento no Brasil era de 210, e o estado do Rio de Janeiro respondia por $9 \%$ desse total (Tabela 1). Entre os sete estados com o maior número de cursos de farmácia, o Rio de Janeiro possuía a menor concentração de cursos em relação a sua população: um curso para cada 809 mil habitantes. 
Tabela 1. Número de cursos superiores de farmácia no Brasil, em função de alguns estados da federação.

\begin{tabular}{lcccc}
\hline \multicolumn{1}{c}{ ESTADO } & $\begin{array}{c}\text { NÚMERO } \\
\text { DE CURSOS }\end{array}$ & $\%$ & $\begin{array}{c}\text { POPULAÇÃO } \\
\text { (MILHOES) }\end{array}$ & $\begin{array}{c}\text { № DE HABITANTES } \\
\text { POR CURSO(MIL) }\end{array}$ \\
\hline Espírito Santo & 9 & 4,3 & 3,41 & 379 \\
Minas Gerais & 25 & 11,9 & 19,24 & 770 \\
Paraná & 22 & 10,5 & 10,26 & 466 \\
Rio de Janeiro & 19 & 9,0 & 15,38 & 809 \\
Rio Grande do Sul & 17 & 8,1 & 10,85 & 638 \\
Santa Catarina & 11 & 5,2 & 5,87 & 534 \\
São Paulo & 62 & 29,5 & 40,44 & 652 \\
\hline
\end{tabular}

Fonte: Censo de 2004 do ensino superior publicado pelo INEP/MEC.

O estudo, realizado com base na análise das ementas das disciplinas de homeopatia, mostrou que as faculdades públicas de farmácia apresentam uma abordagem satisfatória do ensino de homeopatia, no que se refere à teoria e à prática. No entanto, não se tem clareza, no estado do Rio de Janeiro, sobre a condição do ensino de homeopatia nas instituições privadas, tendo em vista que seus cursos de graduação em farmácia se iniciaram há poucos anos, e muitos ainda não formaram suas primeiras turmas. De 2004 até 2006, muitas mudanças ocorreram na oferta da disciplina de homeopatia nas faculdades privadas, o que se deve sobretudo ao fato de as turmas atingirem o ciclo profissional do curso e as coordenações de cursos verificarem as lacunas inerentes à formação homeopática. No estado do Rio de Janeiro, 90\% dos cursos de farmácia (18 cursos) são de instituições privadas (INEP, 2006). No primeiro semestre de 2008 , teve início a graduação em farmácia de mais uma instituição pública, o Centro Federal de Educação Tecnológica de Química de Nilópolis - RJ, já constando de sua matriz curricular a disciplina de homeopatia, com sessenta horas e caráter obrigatório.

Segundo Fernandes (2001), cerca da metade dos cursos superiores de farmácia do Brasil apresentavam em seu currículo, em 2001, a disciplina de farmacotécnica homeopática, na maioria dos casos com caráter optativo. Dez a $12 \%$ dos cursos a estavam implantando; $5 \%$ possuíam o conteúdo de homeopatia inserido no programa de outra disciplina; e 35\% não ofereciam ensino de homeopatia. A carga horária ministrada era muito diversificada, oscilando entre cinqüenta e cento e cinqüenta horas. Os conteúdos também eram diversificados e apresentavam lacunas referentes a determinados temas como filosofia homeopática, técnicas de manipulação, estrutura organizacional da farmácia homeopática e garantia de qualidade dos produtos homeopáticos.

No Rio de Janeiro, com outra realidade, quatro anos após a publicação das Diretrizes Curriculares para os Cursos de Farmácia, em 2002, a maioria dos cursos de farmácia, 80\% (16 cursos), ofereciam a disciplina em caráter obrigatório; $15 \%$ (três) a ofereciam de maneira optativa; e 5\% (um) não ofereciam a disciplina (Figura 1). É interessante observar que as instituições públicas somente oferecem essa disciplina em caráter optativo, enquanto $90 \%$ das privadas a oferecem inserida, em sua matriz curricular, de maneira obrigatória. A carga horária média da disciplina nos cursos é de oitenta horas, variando de quarenta a cento e oitenta horas. 
ENSINO DE HOMEOPATIA NA GRADUAÇÃO...

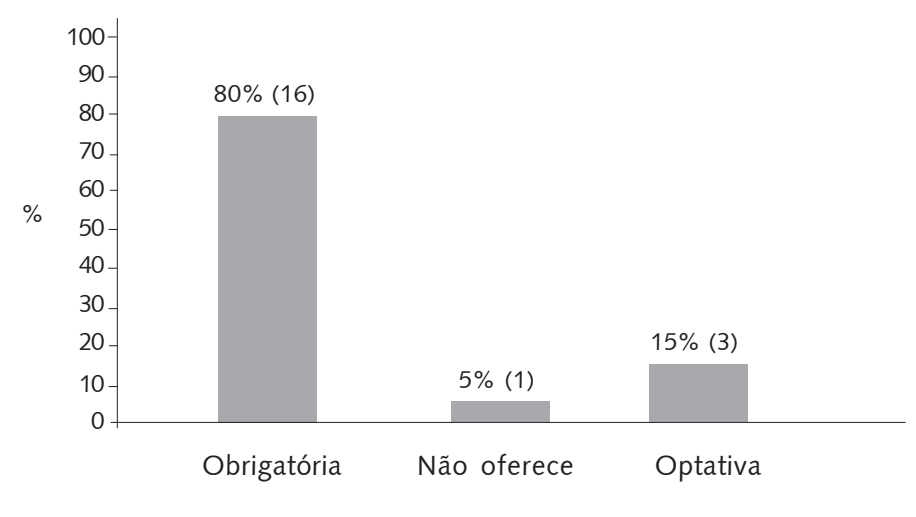

Figura 1. Características da disciplina de homeopatia oferecida nos cursos superiores de farmácia no estado do Rio de Janeiro.

\section{O caso da Faculdade de Farmácia da UFRJ}

Na Faculdade de Farmácia da UFRJ, o novo projeto pedagógico do curso, que possibilitará a formação do farmacêutico generalista, concluído por uma comissão, foi aprovado na congregação da Faculdade de Farmácia em 3 de junho de 2004, e a matriz curricular obteve aprovação em 15 de julho de 2004. A Câmara de Currículo do Conselho de Ensino de Graduação (CEG), reunida em 15 de maio de 2007, aprovou o projeto pedagógico do curso de farmácia, sendo essa a última etapa de tramitação do projeto antes de sua implementação. Havia a proposta de introdução da nova matriz curricular para o primeiro semestre de 2005; porém, sua implementação só foi efetivada no primeiro semestre de 2008. A carga horária total do novo curso será de 5.285 horas ( 252 créditos), realizadas em dez períodos letivos, sendo 4.185 horas de aulas e mil e cem horas de estágios. Criou-se a obrigatoriedade de o aluno cursar disciplinas optativas de escolha condicionada (quatrocentos e cinqüenta horas, trinta créditos) e de livre escolha (dez créditos), totalizando seiscentas horas (quarenta créditos); dessa forma, contribuiu-se para a flexibilização curricular. A homeopatia, nessa nova matriz curricular, estará entre as optativas de escolha condicionada. O aluno, para integralizar o curso de farmácia, deverá cursar um mínimo de trinta créditos de disciplinas optativas disponíveis na grade curricular do curso, de um total de 144 créditos oferecidos.

Os conteúdos de homeopatia foram inseridos na disciplina de farmacotécnica, no início da década de 1990, graças à insistência da professora Marta Côrtes Duarte, que era homeopata e ministrava a disciplina de física industrial. A disciplina era oferecida como se tivesse caráter obrigatório, pois o professor A - naquela época, o responsável pela Farmacotécnica - cedia o horário do que se chamava estudo dirigido para que a disciplina de homeopatia tivesse duração de duas horas semanais, dentro da disciplina "Farmacotécnica II". Dessa forma, a homeopatia foi ministrada, durante mais de quatro anos, até o falecimento da professora Marta. O professor A, embora fosse um opositor da homeopatia, via-a também como uma grande área de atuação do farmacêutico, e acreditava ser obrigação da universidade formar o aluno nessa área. Passou, então, a convidar farmacêuticos para ministrarem essa disciplina. A disciplina passou a ser eletiva, e o farmacêutico homeopata B, que posteriormente coordenaria a especialização em Farmacotécnica Homeopática do Instituto Hahnemanniano do Brasil, ministrou essa disciplina como optativa durante três ou quatro anos, embora não fosse contratado como professor da instituição e nem remunerado. Além disso, tinha ainda que providenciar sala e retroprojetor. Em função das difíceis condições enfrentadas, o professor decidiu parar de ministrar a disciplina; outros farmacêuticos externos à instituição ministraram aulas do mesmo modo e, quando tal prática chegou a 
um ponto insustentável, o professor C, da UFRJ, que sempre estudou homeopatia, decidiu assumir o ônus da disciplina, exigindo, apenas, alguém que o auxiliasse. Sugeriu o professor $D$, por lecionar farmacotécnica e por existir uma relação entre as duas farmacotécnicas, a homeopática e a alopática. $\mathrm{O}$ professor $\mathrm{D}$ relutou em assumir tal responsabilidade, mas acabou aceitando o desafio e foi fazer o curso de especialização do IHB, apaixonando-se pela homeopatia de tal forma que hoje está trabalhando com pesquisa nessa área. À época, a disciplina passou a ser ministrada de forma optativa. Nunca houve um concurso para professor de homeopatia, e os professores C e D dividem seu tempo com outras disciplinas e a chefia de departamento.

Até o ano de 2006, a disciplina de homeopatia era oferecida uma vez por ano, com carga horária de sessenta horas, na forma optativa, mas o aluno não tinha obrigação de cursar nenhum crédito de disciplinas optativas. Em média, havia 25 alunos por turma; porém, segundo o professor $C$, apenas "cerca de cinco alunos (20\%) concluíam o estágio de duzentos e quarenta horas e retornavam para pedir declaração e serem habilitados junto ao CRF em farmácia homeopática".

O professor $\mathrm{D}$ acha "que uma disciplina de introdução à homeopatia deveria ser obrigatória; deveria valer a resolução de 1952, que diz que o curso de farmácia deveria ter em seu currículo noções de farmacotécnica homeopática". Na visão do professor, essa "é uma área de conhecimento do farmacêutico e, assim, o farmacêutico não pode passar pela graduação sem saber o que é homeopatia, até mesmo por uma questão de conhecimento geral". Afirma que não conseguiu colocar a disciplina como obrigatória "porque ainda existe muito preconceito dentro do meio científico com relação à homeopatia, embora a gente saiba que toda a história da homeopatia já tem uma solidez científica muito grande, aqui na UFRJ". O professor C concorda com esse ponto de vista e relata que "outros professores do curso chegam a debochar sobre a existência da homeopatia no departamento de medicamentos"; porém, acredita que é melhor que a disciplina seja optativa, pois entende que, dessa maneira, haverá alunos mais interessados.

As estratégias para motivar os alunos são: uma aula de homeopatia com duas horas de duração na disciplina "Programa de Orientação Acadêmica I: introdução às ciências farmacêuticas" e oferecimento anual de curso extracurricular, com seis horas de duração, ministrado nas Semanas de Farmácia, além da pesquisa na área de homeopatia, com o oferecimento de bolsas de iniciação científica aos alunos.

\section{O caso da Faculdade de Farmácia da UFF}

A partir da década de 1980, como não existia o ensino formal de homeopatia nas faculdades de farmácia, constituíam-se grupos de estudos de homeopatia nas universidades pelo Brasil afora. Na Faculdade de Farmácia da UFF não foi diferente: entre 1982 e 1984, no Grupo de Estudo Homeopático, os alunos realizavam reuniões para dividir leituras, e também convidavam profissionais para ministrarem palestras. Esse grupo organizou em Niterói o Encontro Nacional dos Estudantes Interessados em Homeopatia, e, a partir daí, conseguiu aprovar, no colegiado do curso, a entrada da disciplina farmacotécnica homeopática. Aprovou-se a disciplina, mas não se abriu o concurso para docente; então, a disciplina passou a existir na teoria, mas não na prática. O mesmo ocorreu em várias universidades brasileiras, algumas mais resistentes do que outras. No entanto, a UFF sempre esteve à frente desse movimento.

Em 1996, ocorreu o primeiro concurso para professor de farmacotécnica homeopática da UFF. Atualmente, o corpo docente dessa universidade para as disciplinas de homeopatia é composto por dois efetivos, concursados para as cadeiras de homeopatia, dois docentes substitutos com contrato temporário e mais uma professora da faculdade de medicina que ministra a disciplina de introdução à homeopatia. O professor E considera que hoje se conseguiu institucionalizar a homeopatia na UFF, ou seja, a homeopatia nessa instituição não está presa a pessoas.

A Faculdade de Farmácia da UFF possui três disciplinas de homeopatia, oferecidas semestralmente, todas optativas. A primeira é de introdução à homeopatia, com trinta horas, sem pré-requisito. $\mathrm{O}$ aluno pode se inscrever na disciplina desde o primeiro período. O coordenador, em certas ocasiões, necessita solicitar a ampliação do número de vagas, pois essa disciplina é ministrada pela faculdade de medicina. A segunda trata de farmacotécnica homeopática, com noventa horas, e tem como pré-requisito a farmacotécnica. Nessa disciplina, o aluno pode se inscrever a partir do sétimo período. Por fim, a 
terceira aborda práticas de manipulação e dispensação de medicamentos homeopáticos (estágio), com 165 horas; nesta o aluno só pode se inscrever após ter concluído a disciplina de farmacotécnica homeopática. Esta terceira disciplina teve sua carga horária ampliada para duzentos e quarenta horas, a fim de se enquadrar na resolução n.440/2005 e possibilitar ao aluno assumir a responsabilidade técnica de estabelecimentos homeopáticos. O novo currículo terá a disciplina de introdução à farmácia, que abordará uma parte do conteúdo da introdução à homeopatia.

O professor $\mathrm{F}$ considera que o novo currículo já deveria ter sido implementado, apesar de acreditar que deva haver mais discussão. Tendo discutido a questão em diversos fóruns de coordenadores, atesta que todas as instituições federais têm passado pelo mesmo problema. "Enquanto as disciplinas forem um castelo todo-poderoso, cercado por muros intransponíveis, protegido por um feudo que é o departamento e através do corporativismo, mudanças mais profundas não irão acontecer", diz. Não se sabe quando será implementado o novo currículo - talvez em 2009, pois ele não entrou no edital do vestibular de 2008.

Para a coordenação, pelo menos a disciplina de introdução à homeopatia deveria ser obrigatória, pois, nesse caso, o aluno teria ao menos a noção do que é homeopatia. Os professores E e G acreditam que a informação sobre a filosofia homeopática é indispensável na formação de um farmacêutico com uma visão generalista, mas que uma disciplina mais aprofundada não deve ser obrigatória, pois, segundo o professor G, quando se pensa em uma disciplina obrigatória que todos têm de fazer, é difícil sensibilizar alguém que seja completamente avesso a ela. Segundo esse professor: "as informações básicas têm que ocorrer, e estarão privilegiadas na introdução à farmácia e em vários outros eventos que ocorrem na UFF em relação à homeopatia. Não é uma área que não tenha impacto no aluno de farmácia: na experiência que nós temos, as turmas da faculdade são de cinqüenta alunos, nos chegam trinta para a primeira disciplina prática e, para a segunda disciplina, normalmente, nos chegam vinte a 25 alunos, pois nem todos querem viver essa etapa". Levando-se em consideração que a disciplina só pode ser cursada após o sexto período e que nessa etapa do curso muitos alunos já se evadiram da Faculdade, esse número pode ser considerado expressivo. Afirma o professor E: "Sou professor da disciplina como optativa há dez anos. Nesses dez anos, a disciplina evoluiu bastante; hoje em dia, nós temos um laboratório próprio, atendemos a população, e a minha experiência é a seguinte: em primeiro lugar a matéria é optativa, mas a maioria dos alunos, eu diria que mais de $90 \%$, fazem questão de cursar a disciplina. As pessoas que cursam a disciplina o fazem porque têm interesse em homeopatia e não porque são obrigadas; então, eu vejo realmente com medo o fato de você torná-la obrigatória e um aluno com um perfil completamente distinto ser obrigado a fazê-la para ganhar nota, sem ter interesse pela disciplina, e com isso você acabar alterando o nível do curso".

A maioria dos alunos cursa as disciplinas de homeopatia; alguns, depois de formados, pedem reingresso para fazer a disciplina de prática (estágio). A UFF realiza muitos projetos de extensão. Além de vários projetos de pesquisa serem aplicados e de haver interação com a comunidade, muitas ações de homeopatia no município são abertas, e a comunidade as conhece. Niterói é uma grande cidade universitária em que a integração da comunidade com a universidade é muito efetiva. O curso de homeopatia é sustentado pela farmácia universitária, que gera recursos e na qual os alunos podem realizar as aulas práticas e o estágio.

\section{O caso das faculdades de farmácia das IES privadas}

O estudo evidenciou que as faculdades de farmácia das IES particulares estão praticamente enquadradas nas novas diretrizes curriculares, porque os seus cursos superiores de farmácia já se apresentam no modelo generalista.

Constatou-se que a maioria das faculdades oferece a disciplina de homeopatia de maneira obrigatória, em regime semestral. Por outro lado, na maior parte dessas faculdades, o estágio não é oferecido na própria instituição, mas as aulas práticas são ministradas em laboratórios multidisciplinares, e as faculdades não possuem Farmácia-Escola. Não existe pesquisa científica na área farmacêutica nessas instituições, e os alunos são sempre levados às visitas técnicas e estimulados a realizar trabalhos de extensão.

A introdução das disciplinas de homeopatia respondeu à necessidade que essas faculdades 
identificaram no mercado de trabalho e na formação do farmacêutico homeopata. O curso de especialização existente era pago e durava dois anos, mas, como era possível obter habilitação junto ao CRF cursando uma disciplina na graduação e fazendo um estágio, a maioria dessas instituições optou por oferecer essa formação no próprio curso de graduação. Depois, em 2002, quando as novas diretrizes curriculares para os cursos de farmácia foram publicadas, as IES particulares entenderam que a farmácia homeopática, como área exclusiva do farmacêutico, deveria, obrigatoriamente, estar presente no novo currículo generalista. Isto tudo só pode ocorrer graças à maior flexibilidade que essas IES têm em adequarem seus currículos, e à preocupação em estarem em consonância com o mundo produtivo.

\section{Perspectivas: ensino de homeopatia e mercado de trabalho}

Os cursos de farmácia no estado do Rio de Janeiro tiveram um crescimento exacerbado a partir de 1999 (Figura 2). Em um período de cinco anos, foram implementados cerca de $80 \%$ dos cursos existentes no estado, todos em instituições privadas; a relação de cursos entre as instituições públicas e privadas teve uma queda de $50 \%$ para $10 \%$. Atualmente, apenas $11,7 \%$ das vagas oferecidas nos cursos de farmácia do estado do Rio de Janeiro estão em instituições públicas, sendo seus cursos ministrados em horário integral; não se oferecendo vagas noturnas, impede-se o acesso dos indivíduos que precisam trabalhar. Além do mais, a meta do atual governo federal é que 30\% das vagas oferecidas sejam oriundas de instituições públicas (Figura 3). Atualmente, há vinte cursos ministrados em 14 IES.

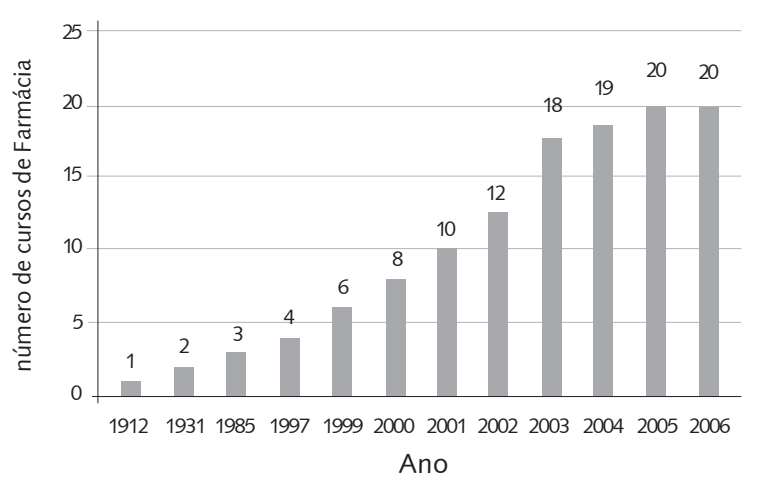

Figura 2. Evolução da abertura de cursos superiores de farmácia no estado do Rio de Janeiro (INEP, 2006).

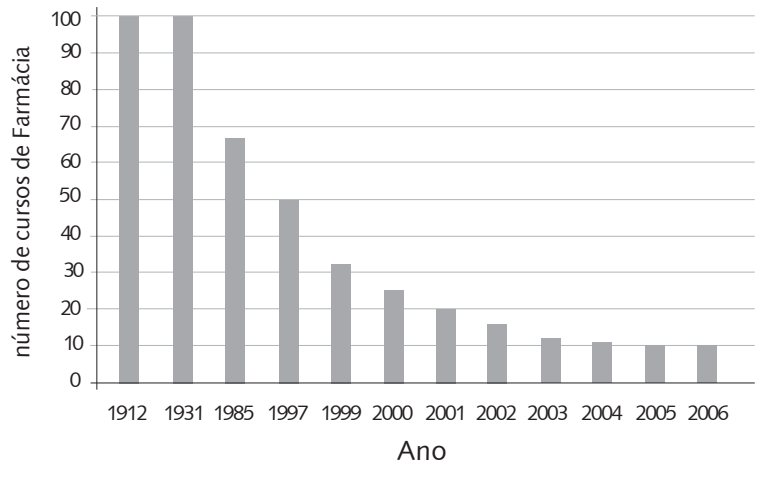

Figura 3. Relação entre o número de cursos oferecidos por instituições públicas e instituições privadas ao longo dos anos no estado do Rio de Janeiro.

A Figura 4 mostra a evolução do número de farmácias homeopáticas ao longo dos anos. Foi constatado um significativo aumento desse número no estado do Rio de Janeiro do ano 2000 ao ano 2005, atingindo, nesse último ano, cerca de duzentos estabelecimentos. Além disso, a curva ajustada aos pontos, de modelo exponencial, mostra a tendência de aumento do número de farmácias homeopáticas nos próximos anos. 
ENSINO DE HOMEOPATIA NA GRADUAÇÃO..

Outro fato constatado foi que, a partir de 1980, com o reconhecimento oficial da homeopatia como especialidade médica, houve um aumento expressivo no número de farmácias homeopáticas no Rio de Janeiro, que permite considerar essa década como a de maior crescimento da homeopatia. Por outro lado, isso também pode estar relacionado com a abertura de mercado que o Brasil sofreu após o período de ditadura militar. No entanto, cabe citar que a existência da lei n.1.552, de 8 de julho de 1952, propiciou a obrigatoriedade do ensino de farmacotécnica homeopática nas faculdades de farmácia do Brasil a partir dos anos de 1950. Ao contrário do que se esperava, não foi observado um aumento significativo do número de farmácias homeopáticas entre os anos 1950 e 1980.

As entrevistas realizadas com os professores de homeopatia indicaram que a maioria deles acredita que o mercado de trabalho do farmacêutico homeopata está em franca expansão, embora haja uma tendência à estabilização. Alguns professores lembraram que muitas farmácias com manipulação alopática começaram a manipular medicamentos homeopáticos, passando a contratar farmacêuticos homeopatas, porque o responsável técnico por esse setor deve possuir a habilitação em homeopatia e, sendo farmacêutico, também pode acumular a função de responsável pelas outras áreas alopáticas da farmácia.

As exigências das legislações da Agência Nacional de Vigilância Sanitária (ANVISA) fizeram com que as farmácias homeopáticas tivessem que contratar farmacêuticos cada vez mais capacitados. Em função disso, há um maior número de vagas para profissionais qualificados.

Desde 1982, a questão do ensino de homeopatia vem sendo debatida, particularmente no que diz respeito à formação do médico (Tucunduva Neto, 1984; Oliveira, 1983, 1982; Linhares, 1982).

Atualmente, com a reformulação do ensino em praticamente todas as faculdades de farmácia, por efeito das novas diretrizes curriculares elaboradas pelo $\mathrm{CNE}$, o ensino de homeopatia voltou a ser o foco das atenções.

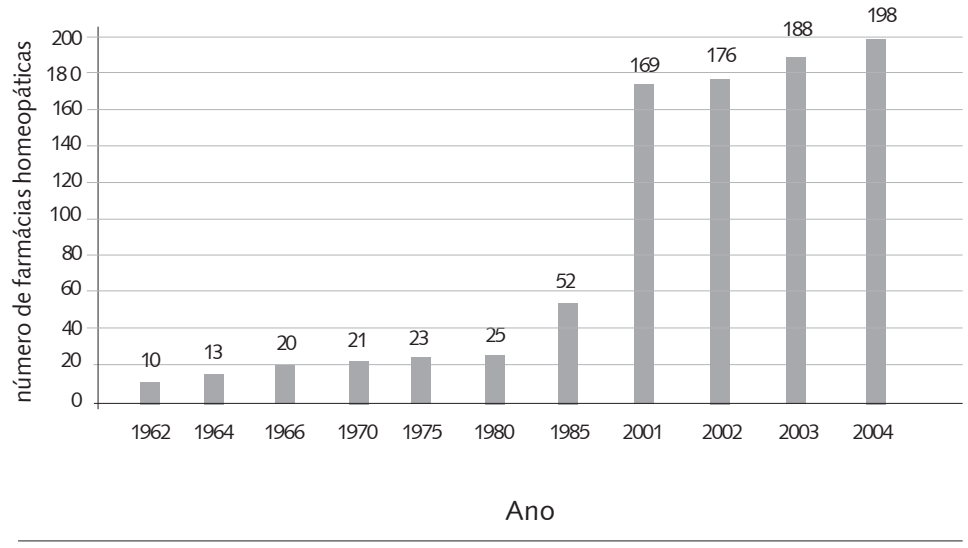

Figura 4. Evolução do número de farmácias homeopáticas ao longo dos anos no estado do Rio de Janeiro. Dados obtidos no CRF-RJ de 2005.

Miranda (2001) analisou a institucionalização da prática farmacêutica homeopática no SUS nas cidades de Niterói, Rio de Janeiro e Juiz de Fora. Dantas (2002) realizou um estudo com 51 estudantes de medicina presentes no XXXV Congresso Brasileiro de Educação Médica, com o objetivo de identificar as atitudes de estudantes interessados em ensino médico em relação a quatro práticas médicas heterodoxas, entre as quais a homeopatia. Trovo, Silva e Leão (2003) procederam à análise do 
conhecimento dos acadêmicos de enfermagem sobre terapias alternativas/complementares no ensino público e no privado. Teixeira, Lin e Martins (2005) pesquisaram as atitudes dos acadêmicos em relação ao ensino da homeopatia e da acupuntura na Faculdade de Medicina da Universidade de São Paulo. Nenhum desses estudos, no entanto, investigou o ensino da homeopatia em faculdades de farmácia.

Um fato interessante foi a publicação da portaria interministerial n.610, de 26 de março de 2002 (Brasil, 2002a), dos Ministérios da Saúde e da Educação, que instituiu o Programa de Incentivo às Mudanças Curriculares para as Escolas Médicas, com o objetivo de estimular as faculdades de medicina do país a incorporarem mudanças pedagógicas significativas nos currículos de seus cursos. Essa medida fez com que tais instituições repensassem suas práticas pedagógicas e, em alguns casos, incorporassem o ensino de homeopatia.

O acesso a um mínimo conhecimento de todas as terapias é imprescindível para que profissionais da área da saúde possam saber das limitações de cada uma e escolher o método mais indicado para cada caso específico. Segundo Freire (2001, p.111), "é indispensável que o universitário brasileiro de hoje estude não só teoria, mas também realize observação direta de nossa realidade política e econômica".

O farmacêutico homeopata pode ser visto como um profissional ligado ao ensino, pois, além de produzir medicamentos de qualidade, presta necessariamente assistência ao usuário da homeopatia, que vai à farmácia com muitas dúvidas em relação ao medicamento e, principalmente, à terapêutica. Para o paciente, tudo é novo, e cumpre ao farmacêutico homeopata explicar e acompanhar o tratamento. É ele quem ministra treinamento aos funcionários da farmácia, bem como profere palestras ou explica individualmente o que é homeopatia para o público de pacientes que se submete a esse tratamento (Olney, 2001).

O momento atual é particularmente oportuno para propor um sistema de incentivos às instituições acadêmicas dispostas a adequar a formação profissional que oferecem às necessidades do SUS. Nessa primeira etapa, a proposta dirige-se às escolas médicas, por ser nessa categoria profissional que se apresentam os maiores problemas de formação, com forte tendência à especialização precoce, gerando um perfil profissional inadequado às perspectivas da atenção básica à saúde (Brasil, 2002b). O momento é oportuno para a introdução de disciplinas de homeopatia, pois o SUS já conta com os serviços de clínica e farmácia homeopáticas com forte tendência a se consolidarem, tendo em vista que, em 2004, o Ministério da Saúde organizou, em Brasília, o "1 Fórum Nacional de Homeopatia: a homeopatia que queremos implantar no SUS".

A AMHB elaborou um projeto para a implantação de disciplinas eletivas nas escolas de medicina do Brasil, sugerindo as diretrizes básicas e a grade curricular para um curso com carga horária mínima de 45 horas-aula (Teixeira, Lins, Martins, 2004).

As discussões travadas neste item demonstraram que há um aumento do número de estabelecimentos homeopáticos nos últimos anos, inclusive com aumento do percentual de farmácias com manipulação que produzem medicamentos homeopáticos. Esse percentual, hoje, é de cerca de $50 \%$, sobretudo em função das novas restrições que esse segmento sofreu com relação à legislação sanitária. Assim, o mercado de trabalho para o farmacêutico homeopata deve continuar em crescimento por alguns anos. Por outro lado, acredita-se que os cursos de farmácia tendam a se estabilizar.

Com relação à disciplina de homeopatia, crê-se que deva fazer parte dos currículos de farmácia na forma obrigatória, pois assim o farmacêutico teria o perfil mais próximo do preconizado pelas Diretrizes Curriculares Nacionais do Curso de Graduação em Farmácia, segundo as quais o farmacêutico com formação generalista deve estar capacitado a atuar com todos os tipos de medicamentos. Além disso, há a oportunidade de esse profissional adquirir uma cultura mais ampla dentro de sua área profissional, permitindo-se assim que ele, mesmo sem ser homeopata, faça orientações ao paciente que utiliza duas terapias (homeopática e alopática).

\section{Considerações finais}

A conquista de espaços políticos e curriculares para áreas novas como a homeopatia significa o enfraquecimento de outras áreas, pois vagas para concurso de docentes e recursos, que são escassos, 
ENSINO DE HOMEOPATIA NA GRADUAÇÃO...

terão de ser destinados também à homeopatia. Enquanto isso, áreas que detêm o poder, apesar de apresentarem menor inserção no contexto atual do ensino e no mercado de trabalho, acabam sendo privilegiadas (Lopes, 2004).

[...] algumas pesquisas assumem a separação entre educação, política e poder. Acreditamos que no coração da pesquisa internacional de educação comparada, educação se cruza com poder. [...] as demandas do poder moldam as práticas do conhecimento. (Marginson, Mollis, 2001, p.581)

O estudo revelou que as modificações ocorridas nos currículos das graduações em farmácia, incluindo o ensino de homeopatia, sempre foram movidas por força de lei, baseadas em ações políticas desenvolvidas nos fóruns nacionais e regionais de classe. O ensino de homeopatia no estado do Rio de Janeiro era realizado até 2006 de forma optativa por duas faculdades de farmácia públicas (UFRJ e UFF). A maioria das faculdades particulares oferece esse ensino na forma obrigatória.

Evidenciou-se que a Faculdade de Farmácia da UFRJ manteve, por muitos anos, o mesmo currículo pedagógico da graduação em farmácia. No entanto, em 2004, por força da lei e pelos movimentos políticos internos, ela implementou um novo projeto pedagógico, com a disciplina de homeopatia oferecida como optativa.

No caso da UFF, até os anos 1980, não havia o ensino formal de homeopatia nas faculdades de farmácia. A inclusão desse conteúdo no currículo da graduação em farmácia foi fruto de iniciativas do movimento estudantil. Desde então, a Faculdade de Farmácia da UFF possui três disciplinas optativas de homeopatia, que são oferecidas semestralmente. Por outro lado, o ensino de homeopatia em nível de pós-graduação lato sensu ainda tem sido o caminho para a formação do farmacêutico homeopata. Espera-se, todavia, que essa demanda deva diminuir com o tempo, em virtude da introdução das disciplinas de homeopatia nos cursos de graduação.

Portanto, os resultados sustentam a idéia de que o ensino de homeopatia é importante para a formação do farmacêutico generalista, tendo em vista que a homeopatia constitui uma grande área de atuação para o farmacêutico. A habilitação em homeopatia pode ser encarada como outro atrativo do curso, além de não onerar muito os currículos, uma vez que a carga horária da disciplina de homeopatia é pequena em relação à carga horária total do curso de farmácia.

Espera-se que o presente trabalho apóie a necessária reflexão com relação à introdução do ensino de homeopatia nos cursos de graduação em farmácia.

\section{Referências}

ABFH. Associação Brasileira de Farmacêuticos Homeopatas. Comissão de Ensino. Relatório do II Fórum de Ensino de Homeopatia para Farmacêuticos. Rio de Janeiro, 2000 .

BARDIN, L. Análise de conteúdo. 3.ed. Lisboa: Edições 70, 2004.

BRASIL. Ministério da Educação e Ministério da Saúde. Promed - Portaria Interministerial $n^{\circ}$ 610, de 26 de março de 2002. Institui o Programa Nacional de Incentivo às Mudanças Curriculares para as Escolas Médicas. Brasília, 2002a.

BRASIL. Ministério da Saúde. Portaria n 971, de 3 de maio de 2006. Aprova a Política Nacional de Práticas Integrativas e Complementares (PNPIC) no Sistema Único de Saúde. Brasília, 2006. Diário Oficial da República Federativa do Brasil. Brasília, 2006. Seção 1. Edição n.84. p.20-5. 
BRASIL. Ministério da Saúde. Secretaria de Políticas de Saúde. Uma nova escola médica para um novo sistema de saúde: Saúde e Educação lançam programa para mudar o currículo de medicina. Rev. Saúde Pública, v.36, n.3, p.375-8, 2002b.

CFF. Conselho Federal de Farmácia. Resolução n 440, de 22 set. 2005. Dá nova redação à Resolução no 335/98 do Conselho Federal de Farmácia, que dispõe sobre as prerrogativas para o exercício da responsabilidade técnica em homeopatia. Diário Oficial [da República Federativa do Brasil]. Brasília, DF, n.206, p.147, 26 out. 2005. Seção 1.

Retificação da Resolução no 440, de 22 set. 2005. Dá nova redação à Resolução n० 335/98 do Conselho Federal de Farmácia, que dispõe sobre as prerrogativas para o exercício da responsabilidade técnica em homeopatia. Diário Oficial [da República Federativa do Brasil]. Brasília, DF, n.91, p.91, 15 mai. 2006. Seção 1.

CNE. Conselho Nacional de Educação. Resolução CNE/CES n 2, de 19 de fevereiro de 2002. Institui as Diretrizes Curriculares Nacionais do Curso de Graduação em Farmácia. Diário Oficial [da República Federativa do Brasil]. Brasília, DF, p.9, 4 mar. 2002. Seção 1.

CORRÊA, A.D.; SIQUEIRA-BATISTA, R.; QUINTAS, L.E.M. Similia similibus curentur Notação histórica da medicina homeopática. Rev. Assoc. Méd. Bras., v.43, n.4, p.347-51, 1997.

CORRÊA, A.D. et al. Similia Similibus Curentur: revisitando aspectos históricos da Homeopatia nove anos depois. Hist. Cienc. Saúde - Manguinhos, v.13, n.1, p.13-31, 2006.

DANTAS, F; RIBEIRO, C.T. Atitudes de estudantes de medicina sobre práticas médicas heterodoxas no Brasil. Rev. Bras. Educ. Méd., v.26, n.2, p.99-104, 2002.

DE LA CRUZ, M.G.F. O ensino na Homeopatia na educação farmacêutica. Ensino Soc., v.1, n.1, p.25-32, 2001.

FERNANDES, Z.C. Homeopatizando: e o ensino, como vai? Pharmac. Bras., n.28, p.1921, 2001.

FREIRE, P. Educação e atualidade brasileira. São Paulo: Cortez; 2001.

GALHARDO, J.E.R. História da homeopatia no Brasil. In: CONGRESSO BRASILEIRO DE HOMEOPATIA, 1., 1928, Rio de Janeiro. Anais... Rio de Janeiro: IHB, 1928. p.271-1016.

INSTITUTO NACIONAL DE ESTUDOS E PESQUISAS EDUCACIONAIS - INEP. Disponível em: <http://www.educacaosuperior.inep.gov.br>. Acesso em: 02 jun. 2006.

LEFÈVRE, F.; LEFÈVRE, A.M.C. O discurso do sujeito coletivo: um novo enfoque em pesquisa qualitativa (Desdobramentos). Caxias do Sul: EDUCS; 2000.

LINHARES, W. Ensino uniforme da homeopatia. Rev. Homeop., n.155, p.22-26, 1982.

LOPES, A.C. Políticas curriculares: continuidade ou mudança de rumos? Rev. Bras. Educ., n.26, p.109-18, 2004.

MARGINSON, S.; MOLLIS, M. The door opens and the tiger leaps: theories and reflexivities of comparative education for a global millennium. Comp. Educ. Rev., v.45, n.4, p.581-615, 2001.

MEIRELLES, A.S. Pequena história da homeopatia com suas repercussões na cidade do Rio de Janeiro, no período de 1886 a 1986. Rev. Bras. Homeop., v.1, n.1, p.6-11, 1991. 
MIRANDA, L.M.M. Farmácias homeopáticas: histórias da institucionalização de uma prática. 2001. Dissertação (Mestrado) - Instituto de Medicina Social, Universidade do Estado do Rio de Janeiro, Rio de Janeiro. 2001.

OLIVEIRA, F.D. O ensino da homeopatia: pressupostos filosóficos. Rev. Homeop., v.159, p.21-4, 1983.

Difusão e ensino da homeopatia no Brasil: uma visão estratégica. Rev. Homeop., v.155, p.29-34, 1982.

OLNEY, L.F. Farmácia homeopática: teoria e prática. Barueri: Manole, 2001.

TEIXEIRA, M.Z.; LIN, C.A; MARTINS, M.A. Homeopathy and acupuncture teaching at Faculdade de Medicina da Universidade de São Paulo: the undergraduates' attitudes. São Paulo Med. J., v.123, n.2, p.77-82, 2005.

O ensino de práticas não-convencionais em saúde nas faculdades de Medicina: panorama mundial e perspectivas brasileiras. Rev. Bras. Educ. Méd., v.28, n.1, p.51-60, 2004.

TROVO, M.M. et al. Terapias alternativas/complementares no ensino público e privado: análise do conhecimento dos acadêmicos de enfermagem. Rev. Latinoam. Enferm., v.11, n.4, p.483-9, 2003.

TUCUNDUVA NETO, R.R.C.M. O ensino da homeopatia. Rev. Homeop., v.161, p.12-5, 1984.

CORRÊA, A.D.; LEITE, S.Q.M. Enseñanza de la homeopatía en el grado en farmacia: concepciones y prácticas pedagógicas en instituciones del estado de Rio de Janeiro. Interface - Comunic., Saúde, Educ., v.12, n.25, p.267-80, abr./jun. 2008.

Este artículo investiga la situación de la enseñanza de la homeopatía en las facultades de farmacia del estado de Rio de Janeiro, buscando identificar y analizar la situación político-pedagógica con respecto a la perspectiva curricular de formación del farmacéutico generalista, teniendo en cuenta las Directrices Curriculares Nacionales del Curso de Grado en Farmacia. Se discuten aspectos jurídicos del tema y percepciones de profesores. En el estado de Rio de Janeiro, ofrecen la enseñanza de la homeopatía dos universidades públicas y 12 instituciones privadas; las públicas ofertan la disciplina en forma opcional, y las demás, en forma obligatoria. El estudio demuestra que tanto en el grado como en la especialización en homeopatía, el foco es la preparación de las medicinas, inclusos los contenidos teóricos de la filosofía homeopática.

Palabras clave: Homeopatía. Enseñanza de farmacia. Farmacia. Currículo. Educación superior. 